but sufficient warning and guidance are given to indicate to the reader the statistical nature of certain problems encountered in analytical spectroseopy. The importance of indicating how the errors are distributed in multi-stage analytical techniques and the saving in operational time which can often be attained, without loss of accuracy, by the correct interpretation of the analytical data, are emphasized.

\section{Hydrogen in Jupiter}

Although molecular hydrogen has long been regarded as a constituent of the atmosphere of Jupiter, direct spectroscopic evidence has been lacking. Jupiter has a known mass and size, and the resulting calculated mean density is surprisingly low. When this was considered in relation to the central condensation of the planet as determined from the motions of its satellites, it became clear that much of the planet must be made up of a light substance. The surface gravity on Jupiter is sufficient to retain light gaseous elements, and it seemed likely that hydrogen might be an important constituent at least of the outer layers of Jupiter, and perhaps also of the interior. The spectroscopic detection of molecular hydrogen has proved to be extremely difficult, and it is only possible if a very large quantity of hydrogen is present. The detection rests on a few extremely faint lines of the quadrupole rotation-vibration spectrum of the molecule. It has now been accomplished in the spectrum of Jupiter by C. C. Kiess, C. H. Corliss and Harriet K. Kiess (Astrophys. J. $132,221 ; 1960)$, who found four of the quadrupole lines. In their paper the authors also direct attention to an unexpected excess continuous absorption, which is so far unidentified, but which elosely resembles a known nitrogen tetroxide absorption. Objections to this identification can be raised on the grounds that the hydrogen would act on the tetroxide as a reducing agent, but no other identification has yet been suggested.

\section{Banana Fruit Development}

N. W. Simmonds has reported on experiments on the development of banana fruits and seed fertility, various synthetic auxins and auxin-antagonists being applied to young fruits in lanolin emulsions (Ann. Bot., N.S., 24, 212; 1960). Auxins stimulated the formation of edible pulp in both seedy and parthenocarpic bananas and induced varying degrees of seed fertility. Of the auxin antagonists tried, coumarin stimulated parthenocarpy and induced seed sterility, three others were not or only slightly active, and thiourea markedly inhibited parthenocarpy. Study of the relation between size of mature fruit and seed content indicates that developing seeds stimulate the growth of pulp, and that the amount of stimulation is roughly proportional to the level of parthenocarpy. Fruit development in the banana seems to fit in with Luckwill's general scheme of dual hormonal stimulus.

\section{Pharmacology of Psychotropic Drugs}

THE number of chemical compounds with an effect on the higher centres of the central nervous system has greatly increased in recent years; and the remarkable properties of some of them have aroused much interest in their modes of action, which are now better understood because of improved knowledge of the physiology of the central nervous system. A paper by the Director of Research, Dumex, Ltd., Copenhagen, examines systematically the effects of some of the better known of these psychotropic drugs on the various levels of the central nervous system; their antagonistic and synergistic effects; and the relationship between these effects and the effects on other functional systems and on behaviour. Although the picture revealed is complex and there are many gaps, psychotropic drugs fall into certain classes according to the effects they have, and a system of classification could be developed on this basis. ("The Comparative Pharmacology of Some Psycho. tropic Drugs". E. Jacobson. Offprint from Bull. World Health Org., $21 ; 1960.5 s ., 1$ dollar or Sw. Fr. 3.)

\section{Nomenclature of Human Chromosomes}

The discovery that some errors of sexual development and other congenital defects in man were associated with karyotypic abnormalities has aroused considerable interest, and research in this field is growing rapidly. Already four different states of numerical unbalance of the sex chromosomes have been identified, as well as three primary autosomal trisomic conditions, several examples of karyotypic mosaicism, and other cases attributable to reciprocal translocation and to deficiency. Various systems of numbering of the chromosomes have been used by different research groups, making the comparison of their results difficult. A meeting with the object of trying to devise an agreed nomenclature was therefore arranged by Dr. T. T. Puck, of the University of Colorado, and held in Denver during April 9-11. All those who had contributed to studies of human somatic chromosomes up to the end of 1959 were invited to take part and nearly all were able to attend. Prof. D. G. Catcheside (who acted as chairman), Prof. H. J. Muller and Prof. C. Stern were also present as councillors. A system was agreed on and a statement embodying it and other information relating to the identification of human mitotic chromosomes has been published (Lancet, i, 1063 ; 1960). The statement was signed by all the members, who included five from the United States, three from Britain, three from Sweden, one from France and one from Japan, in addition to those already mentioned. It is hoped that the proposed standard system will be generally adopted, and that any who may prefer to use another scheme will refer to the proposed system and show clearly in what way their own system differs.

\section{Bibliography of Indology}

THE National Library, Calcutta, has published the first volume of "A Bibliography of Indology" (Vol. 1 : Indian Anthropology. Compiled by J. M. Kanitkar. Edited, revised and enlarged by D. L. Banerjee and A. K. Ohdedar. Pp. xi +290 . (Calcutta: National Library, 1960.) Rs. 5.00. 8s.). It is in fact a catalogue of more than 2,000 publications on the archæology and anthropology of the sub-continent, with frequent notes and extracts from reviews describing the contents of the works. Added are author and subject indexes which enable the reader to use conveniently the references. The result is a very useful bibliography, if not entirely complete, particularly on the prehistoric side.

\section{University News :}

Belfast

A CONTRACT has been signed between the Queen's University of Belfast and the United States Navy European Research Contracts Office. Under this contract, in the first year, the University will be supplied with a Deuce electronic digital computer and 